\title{
Linear robust models for international logistics and inventory problems under uncertainty
}

\begin{tabular}{|r|l|}
\hline Journal: & International Journal of Computer Integrated Manufacturing \\
\hline Manuscript ID: & TCIM-2010-IJCIM-0166 \\
\hline Manuscript Type: & Original Manuscript \\
\hline Date Submitted by the \\
Author: & 11-Nov-2010 \\
\hline Complete List of Authors: & Wu, Yue; University of Southampton, School of Management \\
\hline Keywords: & LOGISTICS, GLOBALIZATION, SUPPLY CHAIN MANAGEMENT \\
\hline Keywords (user): & robust optimisation \\
\hline
\end{tabular}

$$
x
$$




\section{Author's response to comments}

\section{Reviewer: 1}

1. Is the subject matter of relevance to manufacturing and appropriate to IJCIM? Is it more suitable to another journal?

YES, it is, though it just covers a problem in logistics. In my opinion, however, the style of the manuscript is too "Operations-Research-oriented".

Author's response: The author agrees with the above opinion. Logistics cost (including inventory cost) accounts for about $10 \%$ of the total cost in developed countries, while it is considerably higher in developing countries. Therefore, manufacturers not only have to consider the manufacturing process/cost, but also logistics process/cost, as the ultimate aim for all supply chains is to satisfy customer demands in a cost effective manner - successful delivery of products to customers is critical for manufacturers.

2. Is the paper a research contribution, or is it a case study, a review, or a discussion? These latter can be acceptable if they make a contribution in their own right.

The paper is a research contribution, in that it presents an optimization model by the author, targeting a problem of international logistics. A case study is used to validate the model.

Author's response: Agree and thanks.

3. Does the paper make a new and significant contribution to the literature in its own area?

The paper presents an interesting model, which addresses a practical problem. The author does not provide any evidence of whether its work is a significant contribution to the literature on international logistics.

Moreover, an article by the same author (If I am nor wrong) has been found, published in 2002 on "Mathematical and Computer Modeling". The article is entitled :"A robust optimization model for a cross-border logistics problem with fleet composition in an uncertain environment". The topic of the two works are basically the same, as well as the approach, though the model notation is somehow different. In the paper under review, no reference has been made to this previous work. Why?

Author's response: Yes, that was the previous work done by the author and others in 2002. We have cited this article (See Page 4). There exist a number of errors in previous work regarding defining the problem, formulations or algorithms. For example,

- It is unrealistic and impractical to define unit trip cost and unit hiring cost as stochastic parameters, as they are hardly changed during the planning horizon in practice.

- It did not consider tans-shipment cost and trans-shipment constraint, which makes all solutions to be infeasible, and the models to be wrong.

- It did not clearly define Solution Robustness and Model Robustness in the logistic model proposed, although these concepts are introduced at the beginning of the previous paper. Therefore, it is hard to know how solution robustness and model robustness are measured in the model.

- It did not define the problem as a two-stage problem. As a result, it failed to demonstrate how they copy with the uncertainty. In this new paper, we develop a two-stage approach to deal with the uncertainty: the first-stage decision is made under uncertain information and the second stage-decision is made after realization of stochasticity.

- It only considered a special case (4-scenario). 
- Regarding computational results, except one test, results of all other tests provided only costs rather than the logistics and inventory decisions to be taken by managers; this is addressed and provided by this new paper.

The contributions/differences of this paper (comparing with the previous one) are:

- The problem is defined as a new logistics and inventory problem between two counties (For example, redefining the unit hiring cost, introducing transshipment cost and trans-shipment constraints, etc.);

- This paper defines the problem as a two-stage problem: the first-stage decision is made before accurate information is available; and the secondstage decision is made after the stochasticity is realized - what action managers should take under every possible scenario that might happen on the delivery day. Therefore, managers can take different actions according to the solutions provided by the model.

- Three different types of robust models are proposed for solving different types of logistics problems: 1) a robust model with solution robustness (for riskaverse managers); 2 ) a robust model with model robustness (if late delivery is allowed); and 3 ) a robust model with trade-off between solution robustness and model robustness (for managers considering both 1) and 2) simultaneously). The previous paper gave only one model with a 4-scenariocase.

- Different types of logistics plans are provided for managers to choose from. We also present further tests to demonstrate the effectiveness of the three models (none of these appeared in the previous work).

4. Does the paper appropriately compare the performance of proposed methodologies with those found in the published literature?

No, it does not. At least this performance is not given in the section with numerical results. See previous comment 3.

Author's response: Please see author's response in 3. In this revised paper, we also add more articles on international road transportation. Please see the first Section.

5. Does the paper provide evidence of real or potential application for advancing manufacturing practice?

No, it does not. The author failed in providing sufficient evidence. The focus of the paper is on the mathematical side of the work, and very little on the way the model could be employed in real world settings by real world decision makers.

Author's response: This paper is motivated by logistics problems that manufacturing companies face under dynamic information, and we use one of the mathematical approaches- robust optimisation-to solve the problem. The solutions provided in Section 4 can help logistics managers to make decisions. For example, Table 3 provides managers different logistics plans (depending on values of parameters $\lambda$ and $\omega$ ), and Table 4 also gives the corresponding costs.

For example, if a manager is risk-averse and doesn't particularly care if all demand is met and all products are delivered, s/he may want to choose the logistics plan with low variability $(\lambda=0.5, \omega=10)$. However, if a manager considers both risk and on-time delivery, s/he may choose the logistics plan when $\lambda=0.5$, $\omega=10$.

Figures $2 \sim 7$ show how parameters $\lambda$ and $\omega$ have an impact on the logistics and inventory system that is developed in this paper.

6. Is it a report of work done by the author(s) and does it state what the author(s) propose to do in the future?

YES, it is a report of a work done by the author. However, nothing is written 
about the future developments the author will try to carry on.

Author's response: Recommendations for future research have been added in the Conclusion Section. Please see the last paragraph of Section 7.

7. Is adequate credit given to other contributors in the field and are references sufficiently complete? (Please indicate any significant omissions.)

The section on literature review is not well organized. The reader cannot tell from this section why the cited papers have been chosen, what are the gaps in the existing literature and which of these gaps are addressed within the manuscript. In such a context, completeness of the given credits could not be proved by the author. Reference to the previous work is not made.

Author's response: We have added more papers in the Literature review part (The last paragraph on Page 2). We also explain the current status in this area (the second paragraph on Page 4).

8. Is the character and contents of the paper clear from its title and abstract? YES, though the title and abstract seem to target international logistics problems in general, while the problem stated in section 2 and then tackled by means of the proposed model is a particular problem.

Author's response: We have slightly changed both the title and the abstract, which the author thinks might better reflect the content.

9. Is the paper clearly, concisely, accurately and logically written? Are there any errors? Could it benefit from condensing or expansion? (Please give details.) The paper is logically written but maybe too much concise. In many points it is not sufficiently clear (see attached comments). Overall, the textual portion of the paper has not been written very accurately. The manuscript needed much more proof-reading (not in terms of written English) to be performed on it BEFORE the submission.

Author's response: In the revision, we have carefully checked the content and revised it accordingly. Additionally, this paper has been proof-read by a professional.

10. Has the paper been written to an acceptable level of English? YES, it has.

Author's response: Thanks.

\section{Reviewer: 2}

1. Is the subject matter of relevance to manufacturing and appropriate to IJCIM? Is it more suitable for another journal?

This paper is loosely related to manufacturing.

Author's response: I appreciate the above comment. Like the review said, it is related to manufacturing (may be not exactly a manufacturing problem). The logistics problem including the transportation plan and inventory plan is one of the important problems that manufacturers have to deal with. The logistics problem becomes more critical when the products are distributed to overseas markets.

2. Is the paper a research contribution, or is it a case study, a review, or a discussion? These latter can be acceptable if they make a contribution in their own right research contribution

Author's response: Agree and thanks.

3. Does the paper make a new and significant contribution to the literature in its 
own area?

a contribution to solve a cross-border global logistic problem (typically between Hong Kong and Mainland China)

Author's response: Agree and thanks.

4. Does the paper appropriately compare the performance of proposed methodologies with those found in the published literature?

yes

Author's response: Agree and thanks. We have cited more articles (See Section 1 ), including some papers published in IJCIM.

5. Does the paper provide evidence of real or potential application for advancing manufacturing practice?

yes

Author's response: Thanks.

6. Is it a report of work done by the author(s) and does it state what the author(s) propose to do in the future?

done

Author's response: Thanks. Add recommendations for future research in the final section (See the Section 7).

7. Is adequate credit given to other contributors in the field and are references sufficiently complete? (Please indicate any significant omissions.)

yes

Author's response: Thanks.

8. Is the character and contents of the paper clear from its title and abstract? yes

Author's response: Thanks. The title has been changed a little to better reflect the content.

9. Is the paper clearly, concisely, accurately and logically written? Are there any errors? Could it benefit from condensing or expansion? (Please give details.) yes

Author's response: Thanks. To further enhance the paper's quality, we have asked a professional to proof-read the paper.

10. Has the paper been written to an acceptable level of English?

yes

Author's response: Thanks. To further enhance the paper's quality, we have asked a professional to proof-read the paper.

Comments to the Author

The paper addresses an important global cross-border logistcs problem. It is well written. However, I am not sure if this topic is suitable for IJCIM as the manufacturing content is not strong.

Author's response: The author agrees with the above opinion. Logistics cost (including inventory cost) accounts for about $10 \%$ of the total cost in developed countries, while it is considerably higher in developing countries. Therefore, manufacturers not only have to consider the manufacturing process/cost, but also the logistics process/cost, as the ultimate aim for all supply chains is to satisfy customer demands in a cost effective manner - successful delivery of products to customers is critical for manufacturers. 


\section{Editor Comments}

1. Please revise your paper and respond to the referees comments in a separate .doc file and submit this with the revised manuscript.

Author's response: All have been done accordingly.

2. Please have your paper proof read by a native English Speaker or a person more familiar with the English language. (See comment 9 from Reviewer 1) Author's response: The paper has been proof-read.

3. Please resubmit you paper in 3 .doc word files for text, figures and tables. Author's response: It has been done accordingly.

\section{Summary of the changes:}

1. Changes in the title, abstract and keywords.

2. Reviews more papers (See the first section about the introduction), including 4 papers in IJCIM.

3. Added the contribution of this paper (See the second paragraph on Page 4).

4. Changed the titles for Sections 4.1., 4.2., 4.3., 5.1., 5.2., and 5.3.

5. Added recommendations for future research (See the last paragraph of Section 7).

6. The paper has been proof-read. 


\title{
Linear robust models for international logistics and inventory problems under uncertainty
}

\author{
Yue $\mathrm{Wu}^{*}$ \\ School of Management, University of Southampton, Highfield, Southampton, the \\ United Kingdom, SO17 1BJ
}

\begin{abstract}
Globalization presents business organizations with some special challenges that they have never met before; they have to manage their activities in the ambit of global supply chain networks. Traditional managerial approaches, techniques and principles are no longer effective in dealing with these challenges. This paper examines logistics and inventory problems in a supply chain operating in two countries where decisions have to be made with uncertain customer information. There are some differentials between two countries in terms of vehicle operation cost and capacity, labour cost, warehousing cost, etc. This paper proposes three different types of robust models to integrate logistics and inventory processes between the two counties for coping with uncertain customer shipment information and the risk it entails. The first model is called the robust optimization model with solution robustness, which provides an integrated logistics and inventory solution that is less sensitive to realizations of stochastic parameters. The second type of model is called the robust optimization model with model robustness allowing late-delivery (if it is profitable). The third type of model is called the robust optimization model with trade-off between solution robustness and model robustness. It provides a direct way to measure the trade-off between risk and cost during the international transportation process. A series of experiments demonstrate that the proposed robust models can provide effective integrated logistics and inventory systems between two countries, which is important in today's highly competitive and dynamic business environment.
\end{abstract}

Keywords: international logistics; inventory; global supply chain; robust optimization; road transport.

${ }^{*}$ Corresponding author: Tel: +44 (0) 238059 8711. Fax: +44 (0) 2380593844

E-mail: y.wu@soton.ac.uk 


\section{Introduction}

Logistics is the process that creates value by timing and positioning inventory; it involves management of order processing, inventory, transportation, and warehousing, materials handling, and packaging as a combined and integrated process in a facility network (Bowersox et al. 2002). Ho et al. (2006) proposed the logistics workflow optimizer, which embraces the combination of On-Line Analytical Processing and Genetic Algorithm to provide decision support in different logistics activities within the supply chain. Yin and Khoo (2007) developed multiple population search strategy for routing selection and sequence optimization of a supply chain. Váncza, et al. (2010) considered a logistics plat form for production network.

International logistics operations occur when supply chains cross national boundaries. An increasingly large number of companies now have significant and growing presence in more than one country. International logistics, therefore, is playing a more and more important role in growth and development of world trade. As firms start operating on a global basis, logistics managers find that traditional methods, techniques, and principles that they have used before are no longer effective. They have to develop innovative strategies in order to compete in the market place. International logistics has drawn significant attention from researchers and practitioners since the 1990s. Cohen and Li (1989) proposed international supply chain models with considerations related to global trade in raw materials, production cost, duties, tariffs, different tax rates among countries, random fluctuations in currency exchange rates, and the existence of other constraints not included in singlecountry models. Goldsborough (1992) provided an analysis of global logistics management where two different logistics systems - domestic and international were compared. Cohen and Mallik (1997) stated in their analytical review of literature on global supply chain that few of the models incorporated price and demand uncertainties in international markets. Coyle et al. (2003) discussed a series of issues and challenges that global logistics face, in terms of road, rail, sea, and air transportation.

Road transport is the most important among all inland transport modes. Muller (1999) noted that in the U.S., of the nearly 7.8 million tons of freight and commodities moved in 1996, an estimated $46 \%$ was moved by truck (up almost $78 \%$ 
since 1980), compared with $26 \%$ by rail, $13 \%$ by water, and $15 \%$ by pipeline. However, road transportation beyond the boundary of a country caught the attention of researchers and practitioners only a few years ago when globalization became an important issue for business organizations. Bergan and Bushman (1998) presented the North America Free Trade Agreement (NAFTA) perspective on cross-border truck transportation between the US, Canada, and Mexico, and emphasized the importance of efficient border-crossing systems. Fraering and Prasad (1999) presented a model to integrate international sourcing and logistics. Bochner et al. (2001) examined the possibility of expediting current port-of-entry processing of commercial vehicles entering the US from Mexico, and provided the basic prototype plan for northbound commercial border inspection stations with automated processing, suggesting binational links to improve cross-border systems' efficiency. Ambrosini and Routhier (2004) compared the objectives, methods and results in urban freight transport with focus on nine industrialized countries of Europe, America and Asia.

International logistics networks need to consider a great deal of uncertainty and risk when making decisions. Most traditional logistics methods assume that all information required for decision-making is known with certainty. However, Reddy and Reddy (2001) stated that in the globalization era, the only constant is change and all decision-making techniques and methods have to factor this into the decisionmaking process. Nowadays, it is difficult to obtain accurate demand information from the markets as information changes over time. In addition, international transportation faces an even more critical situation because moving goods beyond one country usually involves high capital investment and the time required is even shorter, representing more uncertain factors and higher risk. Therefore, solving logistics problems under uncertainty in the global network is critical to success of the whole supply chain. Mulvey et al. (1995) and Mulvey and Ruszczynski (1995) propose robust programming to deal with the risk, and the solutions are progressively less sensitive to the realizations of stochastic parameters. Mulvey et al. (1995) defined two concepts: solution robust and model robust. The optimal solution of the stochastic programming model will be solution robust if it remains 'close' to optimal for all realizations of random variables. The solution will be model robust if it remains 'almost' feasible for any realization of random variables. Robust optimization has a number of applications; callable bonds portfolios problems (Vassiadou-Zeniou and Zenios 1996); incapacitated network design problems (Gutiérrez et al. 1996); 
restricted recourse problems with trade-off between the stability of recourse decisions and the expected cost; the constrained control of systems considering flexibility (Darlington et al. 1999); fleet management problems (List et al. 2003), production loading problems in the global supply chain ( $\mathrm{Wu} 2006)$, production scheduling (Sabuncuoglu and Goren 2009). Yu and Li (2000) developed a robust optimization model for stochastic logistic problems consisting of suppliers, plants and distribution centres, for which they proposed an efficient method to reduce the computational burden in practice. Two logistics examples from a wine company and an airline company are presented to demonstrate the computational efficiency of the method. Leung et al. (2002) proposed a robust model for a cross-border logistics problem between Hong Kong and China. The model does not include the transhipment constraint at the border, which would result in an infeasible solution when demand is not equal to supply. Similarly, the penalty function in the objective function might include negative components when total products shipped and stocked exceed the total demand in Hong Kong. As supply data are not provided in the tests, it is difficult to justify the results. Additionally, the computational results do not give logistics plans in terms of vehicle composition, routes, and inventory level for each scenario that might occur in the future, which should be one of the major outputs for robust models.

From the above literature review, we find that robust optimisation is a useful technique to handle risk; it has been applied in a number of areas. However, there exists little research on using the concept of solution robustness and model robustness to deal with the risk in international logistics and inventory problems under uncertainty. This paper aims to fill this gap.

\section{Problem statement}

In this paper, we consider international logistic problems which involve transporting goods from country A across the border to country B. There are some differentials between two countries in terms of truck operation cost, truck capacity, labour cost, warehousing cost, etc. Compared with country B, country A is a low-cost country in terms of production, transportation, warehouse and labour costs, etc. Two centralized warehouses A and B are located in countries A and B, respectively. It is assumed that both warehouses have enough capacity for storing goods. The unit inventory cost in 
warehouse B is much higher than in warehouse A. As a result, goods are normally stored in warehouse A in country A, and are transported to warehouse B in country B when needed, i.e. when there is a demand for the goods. The logistics company has its own trucks with two licenses and can operate in both countries. However, when the company fleet does not have enough capacity to satisfy demand in country $\mathrm{B}$, the company has to hire additional trucks. There are two types of trucks available for rental: the first type of truck has a license only for country A and can operate only in that country; the second type of truck has two licenses and can operate in both countries. The company has two strategies for delivering goods. The first strategy is to use company-owned trucks and/or hire trucks with two licenses to directly transport goods from warehouse A to warehouse B. The second strategy is to first load the goods into hired trucks with a country A license only. Then the goods are transshipped into company-owned or hired trucks with two licenses at the border in order to get across to country B. The goods cannot stay overnight at the border as there is no warehouse there. Although transhipment involves a certain cost associated with unloading and loading, the company may adopt this strategy as the cost of hiring a truck with a country A license only is very low. Therefore, the road network consists of three routes: Route 1, connecting warehouse A in country A and warehouse B in country B; Route 2, connecting warehouse A and the trans-shipment point at the border in country A; and Route 3, connecting the trans-shipment point at the border in country A and warehouse B in country B. As shown in Figure 1, Routes 1 and 3 include a border-crossing process.

(Figure 1 is about here)

It is assumed that the cost of hiring a truck either with one license or two licenses covers only one trip each day between the two places. If the truck makes two trips, the hiring cost will double and, therefore, the company does not adopt this strategy. If necessary, the company could hire more trucks, as this ensures faster delivery at the same cost. Thus, only company-owned trucks make a round-trip journey every day on Routes 1 and 3. In this paper, supply is defined as the volume of goods stored in warehouse A located in country A. Goods are transported to warehouse B located in country B when demand occurs. Unfortunately, accurate shipment information can be obtained only on the shipping day from customers. However, the company has a 
limited transportation capacity, and has to determine the number and types of trucks that will be hired in the two countries in advance. Therefore, a two-stage logistics strategy for international transportation problems is developed for dealing with uncertain information and short shipment notice. In the first stage, when accurate information is not available, we determine the fleet composition and vehicle routes. In the second stage, on the shipping day, when accurate shipment information is obtained, we need to make responses to different scenarios that might happen on the shipping day.

\section{Notation and definitions}

\subsection{Indices}

$I^{0}=$ set of company-owned trucks with licences to operate in both countries;

$I^{1}=$ set of trucks for hire with a country A licence only;

$I^{2}=$ set of trucks for hire with licenses for both countries;

$J=$ set of routes $J=\{1,2,3\}$;

$T=$ set of time periods;

$K=$ set of round-trips;

$i=$ index of trucks, $i \in I^{0} \cup I^{1} \cup I^{2}$;

$j=$ index of routes, $j \in J$;

$t=$ index of time periods, $t \in T$;

$k=$ index of round-trips, $k \in K$; and

$s=$ index of scenarios, $s \in S$.

\subsection{Parameters}

\subsubsection{Deterministic parameters}

$v_{t}=$ volume of products arriving in country A's warehouse on day $t, t \in T$;

$L_{i}=$ maximum loading capacity of truck $i, i \in I^{0} \cup I^{1} \cup I^{2}$;

$c_{i j}^{0}=$ unit trip cost of company-owned truck $i$ operating on Route $j, i \in I^{0}, j=\{1,3\}$;

$r_{j}=$ a round-trip's time using Route $j, j=\{1,3\}$;

$H=$ maximum working hours for drivers of company-owned trucks per day; $h_{i}^{1}=$ unit hiring cost of truck $i$ operating in country A on Route $2, i \in I^{1}$; 
$h_{i j}^{2}=$ unit hiring cost of truck $i$ operating in countries A and B on Routes $j, i \in I^{2}$, $j=\{1,3\}$;

$w_{0}^{1}=$ initial volume of products stored in warehouse $\mathrm{A}$;

$w_{0}^{2}=$ initial volume of products stored in warehouse B;

$c^{1}=$ unit inventory cost in warehouse $\mathrm{A}$; and

$c^{T}=$ unit cost of trans-shipment at the border.

\subsubsection{Random parameters}

$d_{t s}=$ volume of products demanded in country B on day $t$ for each scenario $s, t \in T$, $s \in S$

$c_{s}^{2}=$ unit inventory cost in warehouse B for each scenario $s, s \in S$;

$c_{s}^{3}=$ unit penalty cost for not satisfying the demand in country B for each scenario $s$, $s \in S$; and

$p_{s}=$ probability for each scenario $s, s \in S$.

\subsection{Decision variables}

\subsubsection{The first-stage decision variables}

The value of the first stage variables is not directly conditioned on realization of random variables. In this paper, the following variables are defined as the first stage variables:

$x_{i j / t}^{0}=\left\{\begin{array}{cc}1 & \text { if company-owned truck } i \text { operates on Route } j \text { on the } k^{\text {th }} \text { round on day } t \\ 0 & \text { otherwise }\end{array}\right.$, $i \in I^{0}, j=\{1,3\}, k \in K, t \in T$;

$X_{i j k t}^{0}=$ volume of goods loaded by company-owned truck $i$ on Route $j$ on $k^{\text {th }}$ round on day $t, i \in I^{0}, j=\{1,3\}, k \in K, t \in T$;

$x_{i t}^{1}=\left\{\begin{array}{cc}1 & \text { if hired truck } i \text { operates from country A to border on Route } 2 \text { on day } t \\ 0 & \text { otherwise }\end{array}\right.$, $i \in I^{1}, t \in T$;

$X_{i t}^{1}=$ volume of goods loaded by hired truck $i$ with one license on Route 2 on day $t$, $i \in I^{1}, t \in T$; 
$x_{i j t}^{2}=\left\{\begin{array}{cc}1 & \text { if hired truck } i \text { operates from country A to country B on Route } j \text { on day } t \\ 0 & \text { otherwise }\end{array}\right.$ $i \in I^{2}, j=\{1,3\}, t \in T$;

$X_{i j t}^{2}=$ volume of goods loaded by hired truck $i$ with two licenses on Route $j$ on day $t, i \in I^{2}, j=\{1,3\}, t \in T$; and $w_{t}^{1}=$ surplus in warehouse A on day $t, t \in T$.

\subsubsection{The second-stage decision variables}

The second stage variables are subject to adjustment once the random variables are realized. The second stage variables include:

$w_{t s}^{2}=$ surplus in warehouse B on day $t$ for each scenario, $t \in T, s \in S$; and $w_{t s}^{3}=$ shortage in country B on day $t$ for each scenario, $t \in T, s \in S$

\subsection{Constraints}

\subsubsection{The first stage constraints}

The first stage constraints have to be satisfied before accurate information is obtained, and they only contain the first stage decision variables.

$$
\begin{aligned}
& v_{t}+w_{t-1}^{1}=w_{t}^{1}+\sum_{k \in K} \sum_{i \in I^{0}} X_{i 1 k t}^{0}+\sum_{i \in I^{1}} X_{i t}^{1}+\sum_{i \in I^{2}} X_{i l t}^{2}, t \in T \\
& \sum_{i \in I^{1}} X_{i t}^{1}=\sum_{k \in K} \sum_{i \in I^{0}} X_{i 3 k t}^{0}+\sum_{i \in I^{1}} X_{i 3 t}^{2}, t \in T \\
& \sum_{j=\{1,3\}} \sum_{k \in K} r_{j} x_{i j k t}^{0} \leq H, i \in I^{0}, j=\{1,3\}, t \in T \\
& x_{i j k t} \geq x_{i j, k+1, t}, i \in I^{0}, j=\{1,3\}, k \in K, t \in T \\
& X_{i j k t}^{0} \leq L_{i} x_{i j k t}^{0}, i \in I^{0}, j=\{1,3\}, k \in K, t \in T \\
& X_{i t}^{1} \leq L_{i} x_{i t}^{1}, i \in I^{1}, t \in T \\
& X_{i j t}^{2} \leq L_{i} x_{i j t}^{2}, i \in I^{2}, j=\{1,3\}, t \in T \\
& x_{i j k t}^{0} \in\{0,1\}, X_{i j k t}^{0} \geq 0, i \in I^{0}, j=\{1,3\}, k \in K, t \in T \\
& x_{i t}^{1} \in\{0,1\}, X_{i t}^{1} \geq 0, i \in I^{1}, t \in T \\
& x_{i j t}^{2} \in\{0,1\}, X_{i j t}^{2} \geq 0, i \in I^{2}, j=\{1,3), t \in T \\
& w_{t}^{1} \geq 0, t \in T
\end{aligned}
$$


Constraint (1) is the supply constraint, which requires the total volume of products that arrive in warehouse B plus the initial inventory to be equal to the sum of volume of products leaving warehouse $\mathrm{B}$ on day $\mathrm{t}$ and volume of products left at the end of the day. Constraint (2) is the trans-shipment constraint, which ensures that the total volume of products arriving at the transhipment point at the border is equal to the total volume of products leaving the trans-shipment point to go to warehouse B on day $t$. This constraint is needed since goods cannot be kept at the trans-shipment point overnight. Constraint (3) ensures that working hours for drivers of company-owned trucks cannot exceed the maximum working hours. Constraint (4) ensures that each company-owned truck could make the next round trip only after the previous round trip has been completed. Constraints (5) (7) are vehicle capacity constraints. Constraints (8) (11) are variable type constraints.

\subsubsection{The second stage constraints}

Constraints consisting of first and second stage variables are referred as second stage constraints, which have to be satisfied after realization of random variables.

$$
\begin{aligned}
& d_{t s}=w_{t-1, s}^{2}+\sum_{k \in K} \sum_{j=\{1,3\}} \sum_{i \in I^{0}} X_{i j k t}^{0}+\sum_{j=\{1,3\}} \sum_{i \in I^{2}} X_{i j t}^{2}-w_{t s}^{2}+w_{t s}^{3}, t \in T, s \in S \\
& w_{t s}^{2}, w_{t s}^{3} \geq 0, t \in T, s \in S
\end{aligned}
$$

Constraint (12) ensures that on day $t$ and in each scenario $s$, the total volume of products transported and received from warehouse A plus the volume of products currently stored in warehouse $\mathrm{A}$ is equal to the total volume of products required in warehouse B plus products stored or product shortage in warehouse B. Constraint (13) is the variable type constraint.

\subsection{Cost}

\subsubsection{The first stage cost}

The first stage cost occurs when first stage decisions are made. It includes the company-owned trucks cost, hiring cost for all trucks, trans-shipment cost, and inventory cost at warehouse A.

$F S=\sum_{t \in T} \sum_{k \in K} \sum_{j=\{1,3\}} \sum_{i \in I^{0}} c_{i j}^{0} x_{i j k t}^{0}+\sum_{t \in T} \sum_{i \in I^{1}} h_{i}^{1} x_{i t}^{1}+\sum_{t \in T} \sum_{j=\{1,3\}} \sum_{i \in I^{2}} h_{i}^{2} x_{i j t}^{2}+\sum_{t \in T} \sum_{i \in I^{1}} c^{T} X_{i t}^{1}+\sum_{t \in T} c^{1} w_{t}^{1}$

\subsubsection{The second stage cost}


The second stage cost will occur when decisions are made after the stochasticity is realized. It is the sum of the expected inventory cost at warehouse B and the shortage cost in country B.

$$
S S=\sum_{s \in S} \sum_{t \in T} p_{s}\left(c_{s}^{2} w_{t s}^{2}+c_{s}^{3} w_{t s}^{3}\right)
$$

\section{Model formulation}

\subsection{A robust model with solution robustness}

A robust optimization model with solution robustness means the solution will not differ substantially under different scenarios and there is less variability in the objective function across different scenarios of the stochastic variables. A robust optimization model with solution robustness for international logistics problems under uncertainty can be formulated as:

$$
\operatorname{Min} F S+S S+\lambda \sum_{s \in S} p_{s}\left\|\left(c_{s}^{2} w_{t s}^{2}+c_{s}^{3} w_{t s}^{3}\right)-S S\right\|
$$

\section{s.t. $(1) \sim(15)$}

In objective function (16), the third term is referred as the expected variability cost, which measures the variability among all realizations of the stochastic variables. In (16), $\lambda$ is a goal programming parameter representing measurement of variability of the second stage constraints, and $\sum_{s \in S} p_{s}\left\|\left(c_{s}^{2} w_{t s}^{2}+c_{s}^{3} w_{t s}^{3}\right)-S S\right\|$ is referred as the expected variability.

\subsection{A robust model with model robustness}

A robust optimization model with model robustness means violation of the second stage constraint is permitted, but this is done to the lowest extent and amount. A robust optimization model with model robustness for international logistics problems under uncertainty can be formulated as:

$$
\operatorname{Min} F S+S S+\omega \sum_{s \in S} \sum_{t \in T} p_{s}\left\|d_{t s}+w_{t s}^{2}-w_{t}^{3}-w_{t-1, s}^{2}-\sum_{k \in K} \sum_{j=\{1,3\}} \sum_{i \in I^{0}} X_{i j k t}^{0}-\sum_{j=\{1,3\}} \sum_{i \in I^{2}} X_{i j t}^{2}\right\|
$$

s.t. (1) $\sim(11)$ and $(13) \sim(15)$

In the above model, the last term is defined as the expected infeasibility cost, which is used to measure the infeasibility of the second stage constraints. In (17), $\omega$ is a 
parameter as a measurement of the infeasibility of the stochastic constraints, and $\sum_{s \in S} \sum_{t \in T} p_{s}\left\|d_{t s}+w_{t s}^{2}-w_{t}^{3}-w_{t-1, s}^{2}-\sum_{k \in K} \sum_{j=\{1,3\}} \sum_{i \in I^{0}} X_{i j k t}^{0}-\sum_{j=\{1,3\}} \sum_{i \in I^{2}} X_{i j t}^{2}\right\|$ is referred as the expected infeasibility.

\subsection{A robust model with the trade-off between solution robustness and model robustness}

When we consider the variability and the infeasibility simultaneously, a robust optimization model featuring the trade-off between solution and model robustness is formulated as:

$$
\begin{aligned}
\operatorname{Min} & F S+S S+\lambda \sum_{s \in S} p_{s}\left\|\left(c_{s}^{2} w_{t s}^{2}+c_{s}^{3} w_{t s}^{3}\right)-S S\right\| \\
& +\omega \sum_{s \in S} \sum_{t \in T} p_{s}\left\|d_{t s}+w_{t s}^{2}-w_{t}^{3}-w_{t-1, s}^{2}-\sum_{k \in K} \sum_{j=\{1,3\}} \sum_{i \in I^{0}} X_{i j k t}^{0}-\sum_{j=\{1,3\}} \sum_{i \in I^{2}} X_{i j t}^{2}\right\|
\end{aligned}
$$

s.t. $(1) \sim(11)$ and $(13) \sim(15)$

\section{Robust linear models}

The robust models proposed in Section 4 belong to non-linear linear programming models, as all models include the term $\|o\|$, representing the norm of $o$. The norm can be chosen in an arbitrary way. Its choice, however, influences solution performance. If the norm is denoted by the variance, the quadratic terms contain numerous cross products among variables, which cause a large computational burden. In this paper, we use the absolute term $|o|$ of $o$ to denote norm $\|o\|$ in the above robust models, and use the method proposed by $\mathrm{Yu}$ and $\mathrm{Li}$ (2000) to convert the robust models into linear models.

\subsection{A linear robust model with solution robustness}

The robust model with solution robustness can be formulated as:

$$
\operatorname{Min} F S+S S+\lambda \sum_{s \in S} p_{s}\left|\left(c_{s}^{2} w_{t s}^{2}+c_{s}^{3} w_{t s}^{3}\right)-S S\right|
$$

s.t. $(1) \sim(15)$ 
$\mathrm{Yu}$ and $\mathrm{Li}$ (2000) proposed a robust model with the absolute term for a logistic management problem, and introduced additional deviation variables to transform the model into a linear programming model. In this paper, we use the same method to transform the above model into a linear model by introducing a deviational variable $\theta_{s} \geq 0$, as follows:

$\operatorname{Min} F S+S S+\lambda \sum_{s \in S} p_{s}\left[\sum_{t \in T}\left(c_{s}^{2} w_{t s}^{2}+c_{s}^{3} w_{t s}^{3}\right)-S S+2 \theta_{s}\right]$

$$
\begin{aligned}
& -\sum_{t \in T}\left(c_{s}^{2} w_{t s}^{2}+c_{s}^{3} w_{t s}^{3}\right)+S S-\theta_{s} \leq 0 \\
& \theta_{s} \geq 0
\end{aligned}
$$

Proof: If $\left(c_{s}^{2} w_{t s}^{2}+c_{s}^{3} w_{t s}^{3}\right) \geq S S$, we have $\theta_{s}=0$. Then the objective function will equal to $F S+S S+\lambda \sum_{s \in S} p_{s}\left(\left(c_{s}^{2} w_{t s}^{2}+c_{s}^{3} w_{t s}^{3}\right)-S S\right)$

If $\left(c_{s}^{2} w_{t s}^{2}+c_{s}^{3} w_{t s}^{3}\right) \leq S S$, we have $\theta_{s}=-\left(c_{s}^{2} w_{t s}^{2}+c_{s}^{3} w_{t s}^{3}\right)+S S$. Then the objective function will equal to $F S+S S+\lambda \sum_{s \in S} p_{s}\left(-\left(c_{s}^{2} w_{t s}^{2}+c_{s}^{3} w_{t s}^{3}\right)+S S\right)$.

\subsection{A linear robust model with model robustness}

The robust model with model robustness in Section 4.2 can be expressed as a linear model by using the absolute term to denote the norm in (17) and introducing a deviational variable $\delta_{t s} \geq 0$.

Min $F S+S S$

$$
+\omega \sum_{s \in S} \sum_{t \in T} p_{s}\left(d_{t s}+w_{t s}^{2}-w_{t}^{3}-w_{t-1, s}^{2}-\sum_{k \in K} \sum_{j=\{1,3\}} \sum_{i \in I^{0}} X_{i j k t}^{0}-\sum_{j=\{1,3\}} \sum_{i \in I^{2}} X_{i j t}^{2}+2 \delta_{t s}\right)
$$

s.t. $(1) \sim(11)$ and $(13) \sim(15)$

$$
\begin{aligned}
& -d_{t s}-w_{t s}^{2}+w_{t}^{3}+w_{t-1, s}^{2}+\sum_{k \in K} \sum_{j=\{1,3\}} \sum_{i \in I^{0}} X_{i j k t}^{0}+\sum_{j=\{1,3\}} \sum_{i \in I^{2}} X_{i j t}^{2}-\delta_{t s} \leq 0 \\
& \delta_{t s} \geq 0
\end{aligned}
$$

\subsection{A robust linear model with trade-off between solution robustness and model robustness}


The robust linear model for international logistics problems under uncertainty is formulated as:

$\operatorname{Min} F S+S S+\lambda \sum_{s \in S} p_{s}\left[\sum_{t \in T}\left(c_{s}^{2} w_{t s}^{2}+c_{s}^{3} w_{t s}^{3}\right)-S S+2 \theta_{s}\right]$

$+\omega \sum_{s \in S} \sum_{t \in T} p_{s}\left(d_{t s}+w_{t s}^{2}-w_{t}^{3}-w_{t-1, s}^{2}-\sum_{k \in K} \sum_{j=\{1,3\}} \sum_{i \in I^{0}} X_{i j k t}^{0}-\sum_{j=\{1,3\}} \sum_{i \in I^{2}} X_{i j t}^{2}+2 \delta_{t s}\right)$

s.t. (1) (11), (13) (15), (21) (22), (24) (25).

\section{Computational results}

\subsection{Deterministic parameters}

All data used in this study are provided by a third-party logistics company. The company has two warehouses: one is located in Mainland China, while the other is in Hong Kong's port terminal. Goods are usually stored at the Mainland China warehouse. The logistics company is responsible for transporting these goods from the Mainland China warehouse to the Hong Kong warehouse. The logistics company under this study has three trucks (V1, V2 and V3). Each truck has a capacity of 250 units. Costs of trips on Routes 1 and 3 are $\$ 300$ and $\$ 200$, respectively. There are 4 trucks (V4, V5, V6 and V7) with a China license that the company can rent. The capacity of each truck is 250 , and the cost of hiring each truck is $\$ 500$. In addition, there are 2 trucks (V8 and V9) with both China and Hong Kong licenses available for rental. Capacity of each of these trucks is 450 . In addition, the cost of hiring the truck bears no relationship to its transportation route. The hiring cost for each truck for each round trip is $\$ 1,500$. Computational results for all of the following tests show that the hired trucks with two licenses will not operate on Route 3 between the border and warehouse B. Round trips time for Routes 1, 2 and 3 is 10 hours, 3 hours and 5 hours, respectively. However, drivers' maximum working time is 10 hours every working day. Unit inventory cost in the China warehouse is $\$ 1$, and unit inventory cost of the Hong Kong warehouse is $\$ 5$. Unit trans-shipment cost is $\$ 0.5$, and unit penalty cost for not satisfying demand is $\$ 12$. We also assume that the two warehouses have enough space to store any volume of goods left. The supply in the Mainland China warehouse is shown in Table 1. 
(Table 1 is about here)

\subsection{Random parameters}

This paper considers shipment demand, unit surplus cost and shortage cost at the Hong Kong warehouse as random parameters, whose values depend on the future economic situation. As economic conditions are uncertain, decision makers can capture future economic conditions only after realization. It is assumed that the future economic situation will fit into one of three possible situations - good, fair and bad with associated probabilities. Let $s_{1}$ represent a good economy with probability $p_{1}$, $p_{1}=\operatorname{Pr}\left\{s_{1}\right\} ; s_{2}$ represents a fair economy with probability $p_{2}, p_{2}=\operatorname{Pr}\left\{s_{2}\right\} ;$ and $s_{3}$ represents a bad economy with probability $p_{3}, \quad p_{3}=\operatorname{Pr}\left\{s_{3}\right\}$. Table 5.6 shows unit surplus cost, unit shortage cost and demand for each scenario.

(Table 2 is about here)

\subsection{Computational results of the robust model with trade-off between solution robustness and model robustness}

We show computational results only for the general robust linear model in Table 3 by setting up $p_{1}=0.1, p_{2}=0.8, p_{3}=0.1$, and different values of $\lambda$ and $\omega$. The related costs are shown in Table 4.

(Tables 3 and 4 are about here)

\subsection{Further tests for the robust models}

In this section, we perform three different tests under different probabilities. Apart from the change in probability of occurrences of the future economic situation, other conditions in the three tests are the same (See Table 2). The test data are shown in Table 5. Test I represents the situation where it is most likely that demand will perform well, Test II is for the situation where it is most likely that the economic condition will be fair (See Section 6.3), and Test III represents the situation where the economy will be poor.

(Table 5 is about here) 


\subsubsection{Tests for the robust model with solution robustness}

We perform four tests for a weekly plan when $\lambda=0,0.1,0.5$ and 0.9 for each test. Table 6 gives computational results regarding the related cost. In a weekly logistics plan, when the value of $\lambda$ increases from 0 to 0.9 , variability decreases by $60.55 \%$, $15.78 \%$ and $6.44 \%$ in Tests I, II and III, respectively. The total cost increases by $12.23 \%, 7.81 \%$ and $19.53 \%$ in Tests I, II and III, respectively.

(Table 6 is about here)

\subsubsection{Tests for the robust model with model robustness}

Table 7 shows the related costs when $\omega=0,5,10$ and 15 in the three tests. When $\omega=0$, there is no delivery in the whole planning horizon because there is no penalty for not satisfying the demand.

(Table 7 is about here)

\subsubsection{Tests for the robust model with trade-off between solution robustness and model robustness}

Table 8 shows the summary of costs incurred in the robust optimization model with trade-off between solution robustness and model robustness in terms of different values of $\lambda$ and $\omega$.

(Table 8 is about here)

From Table 8, we arrive at the following conclusion: there is always a trade-off between variability and infeasibility. The role of weight $\omega$ and $\lambda$ in the robust optimization model objective function is to measure the trade-off between model robustness ("almost" feasible for any realization of all scenarios) and solution robustness ("close" to optimal for any realization of all scenarios). Robust optimization allows for infeasibility in control constraints by means of penalties. When $\omega=0$, there is no penalty for infeasibility of random constraints in the objective function. The infeasibility that represents under-fulfilment attains a higher value. Clearly, decision makers do not adopt this kind of production plans. However, a large weight of $\omega$ shows that the infeasibility penalty dominates the total objective 
function value and results in a higher variability and a higher total cost. This is an inappropriate approach for decision makers who are open to assume risk and prefer to pay less. Therefore, there is always a trade-off between risk and cost. For the decision makers, it is necessary to test the proposed robust optimization with various $\omega$ and $\lambda$ on global logistics problems.

When $\lambda$ is a constant: Figures $2 \sim 3$ denote computational results for Test $I$ in terms of expected variability, expected infeasibility and total cost, when $\lambda=0.1,0.5$ and 0.9 , respectively. Figure 2 shows the trend of the variability when $\omega$ increases. As the weight $\omega$ increases, the variability increases. In particular, when weight $\omega$ is more than 15 variability increases dramatically. After weight $\omega$ reaches 25 , variability does not change. This means that for larger values of $\omega$, the solution obtained approaches "almost" feasible for any realization of scenario $s$. On the other hand, as weight $\omega$ increases, the total under-fulfilment denoted by the infeasibility drops dramatically (see Figure 3). When weight $\omega$ is greater than or equal to 25 , infeasibility is equal to zero. This means there is no under-fulfilment, i.e. all constraints can be satisfied for any scenario. Figure 4 shows the trend of the total cost.

(Figures 2 4 are about here)

When $\omega$ is a constant: Figures 5 7 denote computational results for Test I (See Table 2 ) in terms of expected variability, expected infeasibility and total cost, when $\omega$ increases for $\lambda=0.1,0.5$ and 0.9 , respectively. Figure 5 shows the trend of the variability when $\lambda$ increases for $\omega=5,15,25,35$ and 45 . If $\lambda$ increases from 0.1 to 0.9 , for $\omega=5$, variability decreases from 40 to 0 ; for $\omega=25$, variability decreases from 2281 to 85 ; and for $\omega=35$, variability decreases from 2,437 to 2,083 .

(Figure 5 is about here)

Figure 6 shows the trend of the infeasibility when $\lambda$ increases for $\omega=5,15,25$ and 35 . The greater the value of $\omega$, the less impact value of $\lambda$ has on variability.

(Figure 6 is about here) 
Figure 7 shows the trend of the total cost when $\lambda$ increases for $\omega=5,15,25,35$ and 45. If $\lambda$ increases from 0.1 to 0.9 , the total cost for $\omega=5, \omega=15, \omega=25, \omega=35$ and $\omega=45$ increases by $0.026 \%, 0.274 \%, 2.083 \%, 5.163 \%$, and $6.834 \%$, respectively. Compared with the changes in variability and infeasibility, the total cost increases by only a small amount when $\lambda$ increases. This means that the robust model proposed in this study is not expensive for a low risk dual-response logistics system.

\section{(Figure 7 is about here)}

\section{Summary}

Because of globalization of the economy and the market, there has been a sharp increase in logistics activities between different countries. International transportation problems that occur in global supply chain networks are studied in this paper. This study develops three types of robust optimization models: the robust optimization model with solution robustness, the robust optimization model with model robustness, and the robust optimization model with trade-off between solution robustness and model robustness. These models can be applied to different decision-making processes for international transportation problems that encounter uncertainty and risk. When the objective function under different scenarios is asymmetric and decision makers are risk averse, robust optimization is appropriate. Decision makers can choose international logistics strategies based on their risk appetites. By analysing parameters of the three types of models, decision makers can obtain their favourite route plans with truck composition, as well as warehousing plans.

This paper provides a modelling framework for international logistics and inventory problems under uncertainty. There are several paths we can take for future research. These are:

- The models developed in this paper need input data. The quality of the data clearly affects the solutions offered by the models. Particularly, development of forecasting models for stochastic demand in international logistics is an important area for further investigation.

- Robust optimization models do not provide means of specifying a scenario. Development of means of determining scenarios for different types of 
international logistics and inventory problems is a potential area for further research.

- This paper only examines logistics problems from country A to country B. Simultaneously transporting goods from country B back to country A is a potential research area to examine, which should substantially improve the fleet's efficiency, while reducing logistics costs.

- Future research could consider integrating logistics and inventory processes with manufacturing processes.

\section{Reference}

Ambrosini, C. and Routhier, J., 2004. Objectives, methods and results of surveys carried out in the field of urban freight transport: An international comparison. Transport reviews, 24 (1), 57-77.

Bergan, A.M. and Bushman, R., 1998. Crossing the border: The NAFTA perspective. The first Latin American ITS regional Conference, Buenos Aires, Argentina.

Bochner, B, Stockton, B., Burke, D. and Harrison, R., 2001. A prototype southern border facility to expedite NAFTA trucks entering the United States. The $80^{\text {th }}$ Annual Meeting Proceeding of the Transportation Research Board, Paper Number: 01-0406.

Bowersox, D.J., Closs and Cooper, M.B., 2002. Supply Chain Logistics Management. McGraw Hill, International Edition.

Cohen, M.A. and Lee, H.L., 1989. Resource deployment analysis of global manufacturing and distribution networks. Journal of manufacturing operations Management, 2, 81-104.

Cohen, M.A. and Mallik, S., 1997. Global supply chains research and allocations. Production and Operations Management, 6, 193-210.

Coyle, J.J., Bardi, E.J. and Langley, J.J., 2003. The Management of Business logistics. $7^{\text {th }}$ edition. Thomas Learning, Canada.

Darlington, J., Pantelides, C.C., Rustem, B. and Tanyi, B.A., 1999. An algorithm for constrained nonlinear optimization under uncertainty. Automatica, 35, 217-228.

Fraering, M. and Prasad, S., 1999. International sourcing and logistics: an integrated model. Logistics Information Management, 12 (6), 451-159. 
Goldsborough, W., 1992. Global logistics management: Gaining a competitive edge through integrated systems. Business Intelligence Program, SRI International, Report No. 818,

Gutierrez, G.J., Kouvelis, P. and Kurawarwala, A.A., 1996. A robustness approach to uncapacitated network design problems. European Journal of Operational Research, 94, 362-376.

Ho, G. T. S., Lee, C. K. M., and Ip, A. W. H., 2006. A hybrid intelligent system to enhance logistics workflow: An OLAP-based GA approach. International Journal of Computer, 19 (1), $69-78$.

List, G.F., Wood, B., Nozick, L.K., Turnquist, M.A., Jones, D.A., Kjeldgaard, E.A. and Lawton, C.R., 2003. Robust optimization for fleet planning under uncertainty. Transportation Research Part E: Logistics, 39, 209-227.

Leung, S., Wu, Y. and Lai, K.K., 2002. A Robust Optimisation Model for a CrossBorder Logistics Problem with Fleet Composition in an Uncertain Environment. Mathematics and Computer Modelling, 36, 1221-1234.

Muler, G., Intermodal Freight Transportation, $4^{\text {th }}$ Edition, 1999. Eno Transportation Foundation, Inc., Washington DC, USA.

Mulvey, J.M., Vanderbei, R.J. and Zenios, S.A., 1995. Robust optimization of largescale systems. Operations Research, 43, 264-281.

Mulvey, J.M. and Ruszczynski, A., 1995. A new scenario decomposition method for large-scale stochastic optimization. Operations Research, 43, 477-490.

Reddy, R. and Reddy, S.R., 2001. Supply Chains to Vertical Integration. McGraw Hill, New York, USA.

Sabuncuoglu, I. and Goren, S. 2009. Hedging production schedules against uncertainty in manufacturing environment with a review of robustness and stability research. International Journal of Computer Integrated manufacturing, 2 (22), 138-157.

Váncza, Ó. Egri, P., and Dávid Karnok, 2010, Planning in concert: A logistics platform for production networks. International Journal of Computer Integrated manufacturing, 23 (4), 297-307.

Vassiadou-Zeniou C. and Zenios S.A., 1996. Robust optimization models for managing callable bond portfolios. European Journal of Operational Research, 91, 264-273. 
Wu, Y., 2006. Robust optimisation applied to uncertain production loading problems with importing quota limits under global supply chain environments. International Journal of Production Research, 44, 849-882.

Yin, X. F. and Khoo, L. P., 2007, Multiple population search strategy for routing selection and sequence optimization of a supply chain. International Journal of Computer Integrated manufacturing, 20 (1), 39 - 56.

$\mathrm{Yu}$, C.S. and Li, H.L., 2000. A robust optimization model for stochastic logistic problems. International Journal of Production Economics, 64, 385-397. 
Table 1. Supply

\begin{tabular}{cccccc}
\hline Mon & Tue & Wed & Thu & Fri & Sat \\
\hline 1000 & 1200 & 2000 & 1700 & 1400 & 1500 \\
\hline
\end{tabular}

Table 2: Unit surplus cost, unit shortage cost and demand for each scenario.

\begin{tabular}{lccccccccc}
\hline \multirow{2}{*}{ Scenario } & \multirow{2}{*}{ Probability } & Unit & Unit & & \multicolumn{3}{c}{ Demand } \\
\cline { 5 - 10 } & & surplus cost & shortage cost & Mon & Tue & Wed & Thu & Fri & Sat \\
\hline$s_{1}$ & $p_{1}$ & 6 & 15 & 1100 & 1300 & 2100 & 1800 & 1500 & 1600 \\
\hline$s_{2}$ & $p_{2}$ & 5 & 12 & 1000 & 1200 & 2000 & 1700 & 1400 & 1500 \\
\hline$s_{3}$ & $p_{3}$ & 4 & 10 & 900 & 1100 & 1900 & 1600 & 1300 & 1400 \\
\hline
\end{tabular}

Table 3. The international logistics plan under different $\lambda$ and $\omega$.

\begin{tabular}{|c|c|c|c|c|c|c|c|c|c|c|c|c|}
\hline \multirow[b]{3}{*}{$(\lambda, \omega)$} & \multirow[b]{3}{*}{ Day } & \multicolumn{5}{|c|}{ The first stage decision } & \multicolumn{6}{|c|}{ The second stage decision } \\
\hline & & \multicolumn{2}{|c|}{ Route 1} & \multirow[b]{2}{*}{$\begin{array}{c}\text { Route } 2 \\
\text { Hired } \\
\text { trucks } \\
\text { with one } \\
\text { license }\end{array}$} & \multirow{2}{*}{$\begin{array}{c}\text { Route } 3 \\
\text { Company } \\
\text {-owned } \\
\text { trucks }\end{array}$} & \multirow[b]{2}{*}{$\begin{array}{c}\text { Surplus } \\
\text { in } \\
\text { China }\end{array}$} & \multicolumn{3}{|c|}{ Surplus in HK } & \multicolumn{3}{|c|}{ Shortage in HK } \\
\hline & & $\begin{array}{c}\text { Company } \\
\text {-owned } \\
\text { trucks }\end{array}$ & $\begin{array}{c}\text { Hired } \\
\text { trucks } \\
\text { with two } \\
\text { licenses }\end{array}$ & & & & $s_{1}$ & $s_{2}$ & $s_{3}$ & $s_{1}$ & $s_{2}$ & $s_{3}$ \\
\hline \multirow{6}{*}{$(0.1,20)$} & Mon & T2 (250) & & T4 (250) & T1 (250) & & & & & 100 & & \\
\hline & Tue & $\begin{array}{l}\text { T1 (250) } \\
\text { T2 (250) } \\
\text { T3 (250) }\end{array}$ & $\mathrm{T} 8$ (450) & & & & & & & 100 & & \\
\hline & Wed & $\mathrm{T} 2(250)$ & $\begin{array}{l}\text { T8 (450) } \\
\text { T9 (450) }\end{array}$ & $\begin{array}{l}\text { T4 (100) } \\
\text { T5 (250) } \\
\text { T6 (250) } \\
\text { T7 (250) }\end{array}$ & $\begin{array}{l}\mathrm{T} 1(100) \\
\mathrm{T} 1(250) \\
\mathrm{T} 3(250) \\
\mathrm{T} 3(250)\end{array}$ & & & & 100 & 100 & & \\
\hline & Thu & $\begin{array}{l}\text { T1 (250) } \\
\text { T2 (250) } \\
\text { T3 (250) }\end{array}$ & $\begin{array}{l}\text { T8 (450) } \\
\text { T9 (450) }\end{array}$ & & & 50 & & & 150 & 150 & 50 & \\
\hline & Fri & $\begin{array}{l}\text { T2 (200) } \\
\text { T3 (250) }\end{array}$ & $\begin{array}{l}\text { T8 (450) } \\
\text { T9 (450) }\end{array}$ & & & 50 & & & 250 & 100 & & \\
\hline & Sat & $\begin{array}{l}\text { T1 (100) } \\
\text { T2 (250) } \\
\text { T3 (250) }\end{array}$ & $\begin{array}{l}\text { T8 (450) } \\
\text { T9 (450) }\end{array}$ & & & 50 & & & 350 & 100 & & \\
\hline \multirow{6}{*}{$(0.5,10)$} & Mon & $\begin{array}{l}\text { T2 (250) } \\
\text { T3 (250) }\end{array}$ & & $\begin{array}{l}\text { T4 (250) } \\
\text { T6 (100) }\end{array}$ & $\begin{array}{l}\text { T1 (250) } \\
\text { T1 (250) }\end{array}$ & & & & & & & \\
\hline & Tue & $\begin{array}{l}\text { T1 (250) } \\
\text { T2 }(250) \\
\text { T3 }(250)\end{array}$ & T8 (450) & & & & & & & & & \\
\hline & Wed & $\begin{array}{l}\text { T1 (200) } \\
\text { T2 (250) }\end{array}$ & $\begin{array}{l}\text { T8 (450) } \\
\text { T9 (450) }\end{array}$ & $\begin{array}{l}\text { T4 (250) } \\
\text { T5 (250) }\end{array}$ & $\begin{array}{l}\text { T3 (250) } \\
\text { T3 (250) }\end{array}$ & 100 & & & & & 5 & \\
\hline & Thu & $\begin{array}{l}\text { T1 (250) } \\
\text { T2 }(250) \\
\text { T3 }(250) \\
\end{array}$ & $\begin{array}{l}\text { T8 (450) } \\
\text { T9 (450) }\end{array}$ & & & 150 & & & & & & \\
\hline & Fri & $\begin{array}{l}\text { T2 (200) } \\
\text { T3 (250) }\end{array}$ & $\begin{array}{l}\text { T8 (450) } \\
\text { T9 (450) }\end{array}$ & & & 150 & & & & & & \\
\hline & Sat & $\begin{array}{l}\text { T1 (100) } \\
\text { T2 (250) } \\
\text { T3 (250) }\end{array}$ & $\begin{array}{l}\text { T8 (450) } \\
\text { T9 (450) }\end{array}$ & & & 150 & & & 100 & & & \\
\hline \multirow{6}{*}{$(0.9,45)$} & Mon & $\begin{array}{l}\text { T1 (200) } \\
\text { T2 (250) }\end{array}$ & T9 (450) & $\begin{array}{l}\text { T4 (250) } \\
\text { T6 (250) }\end{array}$ & $\begin{array}{l}\text { T3 (250) } \\
\text { T3 (250) }\end{array}$ & & & & 100 & 100 & & \\
\hline & Tue & $\begin{array}{l}\text { T1 (250) } \\
\text { T2 }(250) \\
\text { T3 }(250) \\
\end{array}$ & T9 (450) & & & & & & 200 & 100 & & \\
\hline & Wed & $\begin{array}{l}\text { T2 (250) } \\
\text { T3 (250) }\end{array}$ & $\begin{array}{l}\text { T8 (450) } \\
\text { T9 (450) }\end{array}$ & $\begin{array}{l}\text { T5 (250) } \\
\text { T6 (250) }\end{array}$ & $\begin{array}{l}\text { T1 (250) } \\
\text { T1 (250) }\end{array}$ & 100 & & & 200 & 200 & 100 & \\
\hline & Thu & $\begin{array}{l}\text { T1 (250) } \\
\text { T2 (250) } \\
\text { T3 (250) }\end{array}$ & $\begin{array}{l}\text { T8 (450) } \\
\text { T9 (450) }\end{array}$ & & & 150 & & & 250 & 150 & 50 & \\
\hline & Fri & $\begin{array}{l}\text { T2 (250) } \\
\text { T3 (250) }\end{array}$ & T9 (450) & & & 150 & & & 350 & 100 & & \\
\hline & Sat & $\begin{array}{l}\text { T1 (100) } \\
\text { T2 (250) } \\
\text { T3 (250) }\end{array}$ & $\begin{array}{l}\text { T8 (450) } \\
\text { T9 (450) }\end{array}$ & & & 150 & & & 450 & 100 & & \\
\hline
\end{tabular}


Table 4. Summary of costs incurred in the international logistics strategy.

\begin{tabular}{lcccccc}
\hline$(\lambda, \omega)$ & $\begin{array}{c}\text { Expected } \\
\text { variability }\end{array}$ & $\begin{array}{c}\text { Expected } \\
\text { infeasibility }\end{array}$ & $\begin{array}{c}\text { Expected } \\
\text { cost }\end{array}$ & $\begin{array}{c}\text { Expected } \\
\text { variability cost }\end{array}$ & $\begin{array}{c}\text { Expected } \\
\text { infeasibility cost }\end{array}$ & $\begin{array}{c}\text { Total } \\
\text { cost }\end{array}$ \\
\hline$(0.1,20)$ & 2121 & 20 & 24520 & 212 & 400 & 25132 \\
\hline$(0.5,10)$ & 18 & 226 & 21942 & 9 & 2257 & 24208 \\
\hline$(0.9,45)$ & 2083 & 0 & 25035 & 1875 & 0 & 26910 \\
\hline
\end{tabular}

Table 5. Three tests.

\begin{tabular}{cccc}
\hline Possibility & Test I & Test II & Test III \\
\hline$p_{1}=\operatorname{Pr}\left\{\mathrm{s}_{1}\right\}$ & 0.8 & 0.1 & 0.1 \\
\hline$p_{1}=\operatorname{Pr}\left\{\mathrm{s}_{1}\right\}$ & 0.1 & 0.8 & 0.1 \\
\hline$p_{1}=\operatorname{Pr}\left\{\mathrm{s}_{1}\right\}$ & 0.1 & 0.1 & 0.8 \\
\hline
\end{tabular}

Table 6. Costs incurred in the robust model with solution robustness under different $\lambda$ in three tests.

\begin{tabular}{cccccccc}
\hline \multirow{2}{*}{ Test } & $\lambda$ & $\begin{array}{c}\text { Expected } \\
\text { variability }\end{array}$ & $\begin{array}{c}\text { First-stage } \\
\text { cost }\end{array}$ & $\begin{array}{c}\text { Second-stage } \\
\text { cost }\end{array}$ & $\begin{array}{c}\text { Expected } \\
\text { cost }\end{array}$ & $\begin{array}{c}\text { Expected } \\
\text { variability cost }\end{array}$ & $\begin{array}{c}\text { Total } \\
\text { cost }\end{array}$ \\
\hline \multirow{4}{*}{ I } & 0 & 4917 & 21800 & 8180 & 29980 & 0 & 29980 \\
\cline { 2 - 8 } & 0.1 & 4917 & 21800 & 8180 & 29980 & 492 & 30472 \\
\cline { 2 - 8 } & 0.5 & 4917 & 21800 & 8180 & 29980 & 2459 & 32439 \\
\hline \multirow{4}{*}{ II } & 0.9 & 2155 & 21800 & 9906 & 31706 & 1940 & 33646 \\
\cline { 2 - 8 } & 0 & 2473 & 22725 & 2235 & 24960 & 0 & 24960 \\
\cline { 2 - 8 } & 0.1 & 2473 & 22725 & 2235 & 24960 & 247 & 25207 \\
\hline \multirow{3}{*}{ III } & 0.5 & 2083 & 21850 & 3185 & 25035 & 1042 & 26077 \\
\cline { 2 - 8 } & 0.9 & 2083 & 21850 & 3185 & 25035 & 1875 & 26910 \\
\hline & 0 & 5436 & 21550 & 3160 & 24710 & 0 & 24710 \\
& 0.1 & 5436 & 21550 & 3160 & 24710 & 544 & 25254 \\
\cline { 2 - 8 } & 0.5 & 5436 & 21550 & 3160 & 24710 & 2718 & 27428 \\
\hline
\end{tabular}

Table 7. Costs incurred in the robust model with model robustness under different $\omega$.

\begin{tabular}{|c|c|c|c|c|c|c|c|}
\hline Test & $\omega$ & $\begin{array}{l}\text { Expected } \\
\text { infeasibility }\end{array}$ & $\begin{array}{c}\text { First-stage } \\
\text { cost }\end{array}$ & $\begin{array}{c}\text { Second-stage } \\
\text { cost }\end{array}$ & $\begin{array}{l}\text { Expected } \\
\text { cost }\end{array}$ & $\begin{array}{c}\text { Expected } \\
\text { infeasibility cost }\end{array}$ & $\begin{array}{l}\text { Total } \\
\text { cost }\end{array}$ \\
\hline \multirow{6}{*}{ I } & 0 & 3910 & 17400 & 0 & 17400 & 0 & 17400 \\
\hline & 5 & 540 & 21800 & 130 & 21930 & 2700 & 24630 \\
\hline & 10 & 520 & 21800 & 300 & 22100 & 5200 & 27300 \\
\hline & 15 & 500 & 21800 & 540 & 22340 & 7500 & 29840 \\
\hline & 20 & 10 & 21800 & 7940 & 29740 & 200 & 29940 \\
\hline & 25 & 0 & 21800 & 8180 & 29980 & 0 & 29980 \\
\hline \multirow{6}{*}{ II } & 0 & 3490 & 17400 & 0 & 17400 & 0 & 17400 \\
\hline & 5 & 230 & 21850 & 40 & 21890 & 1150 & 23040 \\
\hline & 10 & 220 & 21850 & 120 & 21970 & 2200 & 24170 \\
\hline & 15 & 95 & 22725 & 660 & 23385 & 1425 & 24810 \\
\hline & 20 & 10 & 22725 & 1995 & 24720 & 200 & 24920 \\
\hline & 25 & 0 & 22725 & 2235 & 24960 & 0 & 24960 \\
\hline \multirow{5}{*}{ III } & 0 & 3350 & 17400 & 0 & 17400 & 0 & 17400 \\
\hline & 5 & 520 & 20000 & 160 & 20160 & 2600 & 22760 \\
\hline & 10 & 180 & 21550 & 640 & 22190 & 1800 & 23990 \\
\hline & 15 & 120 & 21550 & 1360 & 22910 & 1800 & 24710 \\
\hline & 20 & 0 & 21550 & 3160 & 24710 & 0 & 24710 \\
\hline
\end{tabular}


Table 8. Trade-off between solution robustness and model robustness under different $\lambda$ and $\omega$.

\begin{tabular}{|c|c|c|c|c|c|c|c|c|}
\hline Test & $\lambda$ & $\omega$ & $\begin{array}{c}\text { Expected } \\
\text { variability }\end{array}$ & $\begin{array}{c}\text { Expected } \\
\text { infeasibility }\end{array}$ & $\begin{array}{l}\text { Expected } \\
\text { cost }\end{array}$ & $\begin{array}{c}\text { Expected } \\
\text { variability cost }\end{array}$ & $\begin{array}{c}\text { Expected } \\
\text { infeasibility cost }\end{array}$ & $\begin{array}{c}\text { Total } \\
\text { cost }\end{array}$ \\
\hline \multirow{18}{*}{ I } & \multirow{6}{*}{0.1} & 0 & 0 & 3910 & 1700 & 0 & 0 & 17400 \\
\hline & & 5 & 80 & 550 & 21880 & 8 & 550 & 24638 \\
\hline & & 10 & 250 & 525 & 22050 & 25 & 5250 & 27325 \\
\hline & & 15 & 255 & 452 & 23060 & 26 & 6780 & 29866 \\
\hline & & 20 & 5061 & 10 & 29740 & 506 & 200 & 30446 \\
\hline & & 25 & 4917 & 0 & 29980 & 492 & 0 & 30472 \\
\hline & \multirow{6}{*}{0.5} & 0 & 0 & 3910 & 17400 & 0 & 0 & 17400 \\
\hline & & 5 & 0 & 570 & 21800 & 0 & 2850 & 24650 \\
\hline & & 10 & 126 & 539 & 21940 & 63 & 5392 & 27395 \\
\hline & & 15 & 101 & 471 & 22806 & 50 & 7062 & 29918 \\
\hline & & 20 & 413 & 375 & 24350 & 207 & 7507 & 32063 \\
\hline & & 25 & 4917 & 0 & 29980 & 2459 & 0 & 32439 \\
\hline & \multirow{6}{*}{0.9} & 0 & 0 & 3910 & 17400 & 0 & 0 & 17400 \\
\hline & & 5 & 0 & 570 & 21800 & 0 & 2850 & 24650 \\
\hline & & 10 & 36 & 524 & 22163 & 33 & 5240 & 27463 \\
\hline & & 15 & 101 & 471 & 22806 & 91 & 7062 & 29958 \\
\hline & & 20 & 0 & 389 & 24350 & 0 & 7776 & 32126 \\
\hline & & 25 & 2155 & 0 & 31707 & 1940 & 0 & 33646 \\
\hline \multirow{25}{*}{ II } & \multirow{7}{*}{0.1} & 0 & 0 & 3490 & 17400 & 0 & 0 & 17400 \\
\hline & & 5 & 40 & 230 & 21890 & 4 & 1150 & 23044 \\
\hline & & 10 & 120 & 220 & 21970 & 12 & 2200 & 24182 \\
\hline & & 15 & 85 & 83 & 23575 & 9 & 1243 & 24827 \\
\hline & & 20 & 2121 & 20 & 24520 & 212 & 400 & 25132 \\
\hline & & 25 & 2281 & 10 & 24720 & 228 & 250 & 25198 \\
\hline & & 30 & 2473 & 0 & 24960 & 247 & 0 & 25207 \\
\hline & \multirow{8}{*}{0.5} & 0 & 0 & 3490 & 17400 & 0 & 0 & 17400 \\
\hline & & 5 & 0 & 240 & 2185 & 0 & 1200 & 23050 \\
\hline & & 10 & 18 & 226 & 21942 & 9 & 2257 & 24208 \\
\hline & & 15 & 85 & 83 & 23575 & 43 & 1243 & 24861 \\
\hline & & 20 & 85 & 83 & 23575 & 43 & 1657 & 25275 \\
\hline & & 25 & 115 & 81 & 23608 & 57 & 2020 & 25685 \\
\hline & & 30 & 1022 & 36 & 24400 & 511 & 1090 & 26001 \\
\hline & & 35 & 2083 & 0 & 25035 & 1042 & 0 & 26077 \\
\hline & \multirow{10}{*}{0.9} & 0 & 0 & 3490 & 17400 & 0 & 0 & 17400 \\
\hline & & 5 & 0 & 240 & 21850 & 0 & 1200 & 23050 \\
\hline & & 10 & 11 & 224 & 21960 & 10 & 2243 & 24213 \\
\hline & & 15 & 85 & 83 & 23575 & 77 & 1243 & 24895 \\
\hline & & 20 & 85 & 83 & 23575 & 77 & 1657 & 25309 \\
\hline & & 25 & 85 & 83 & 23575 & 77 & 2072 & 25723 \\
\hline & & 30 & 115 & 81 & 23608 & 103 & 2424 & 26135 \\
\hline & & 35 & 686 & 42 & 24400 & 617 & 1482 & 26499 \\
\hline & & 40 & 686 & 42 & 24400 & 617 & 1693 & 26711 \\
\hline & & 45 & 2083 & 0 & 25035 & 1875 & 0 & 26910 \\
\hline \multirow{23}{*}{ III } & \multirow{5}{*}{0.1} & 0 & 0 & 3350 & 17400 & 0 & 0 & 17400 \\
\hline & & 5 & 160 & 520 & 20160 & 16 & 2600 & 22776 \\
\hline & & 10 & 640 & 180 & 22190 & 64 & 1800 & 24054 \\
\hline & & 15 & 2045 & 113 & 23015 & 205 & 11695 & 24915 \\
\hline & & 20 & 5436 & 0 & 24710 & 534 & 0 & 25254 \\
\hline & \multirow{8}{*}{0.5} & 0 & 0 & 3350 & 17400 & 0 & 0 & 17400 \\
\hline & & 5 & 160 & 520 & 20160 & 80 & 2600 & 22840 \\
\hline & & 10 & 61 & 185 & 22382 & 31 & 1852 & 24264 \\
\hline & & 15 & 597 & 172 & 22296 & 298 & 2581 & 25175 \\
\hline & & 20 & 597 & 172 & 22286 & 298 & 3441 & 26035 \\
\hline & & 25 & 2045 & 113 & 23015 & 1023 & 2826 & 26863 \\
\hline & & 30 & 2045 & 113 & 23015 & 1023 & 3391 & 27428 \\
\hline & & 35 & 5436 & 0 & 24710 & 2718 & 0 & 27428 \\
\hline & & 0 & 0 & 3350 & 17400 & 0 & 0 & 17400 \\
\hline & & 5 & 160 & 520 & 20160 & 144 & 2600 & 22904 \\
\hline & & 10 & 0 & 182 & 22443 & 0 & 1824 & 24267 \\
\hline & & 15 & 0 & 182 & 22443 & 0 & 2736 & 25179 \\
\hline & 0.9 & 20 & 0 & 182 & 22443 & 0 & 3648 & 26091 \\
\hline & & 25 & 0 & 182 & 22443 & 0 & 4560 & 27003 \\
\hline & & 30 & 0 & 182 & 22443 & 0 & 5472 & 27915 \\
\hline & & 35 & 1555 & 118 & 23243 & 1400 & 4134 & 28777 \\
\hline & & 40 & 1535 & 107 & 23658 & 1382 & 4284 & 29325 \\
\hline & & 45 & 5086 & 0 & 24860 & 4577 & 0 & 29537 \\
\hline
\end{tabular}


Route 2

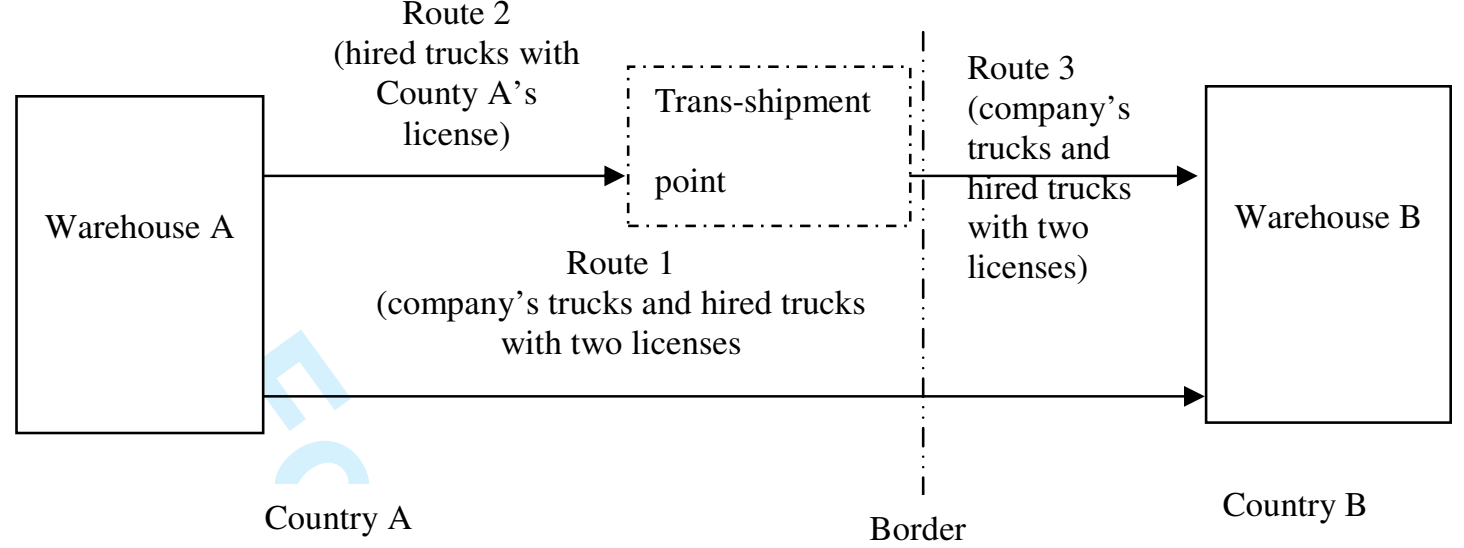

Figure 1. Truck routes.

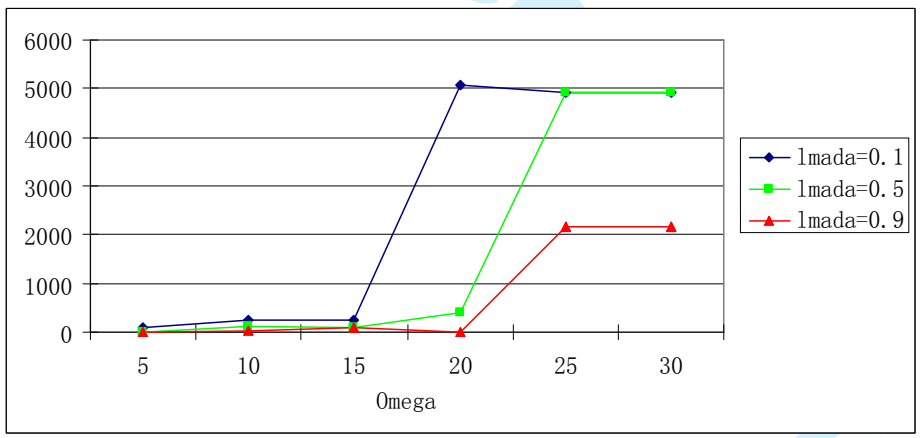

Figure 2. Variability when $\lambda$ keeps constant.

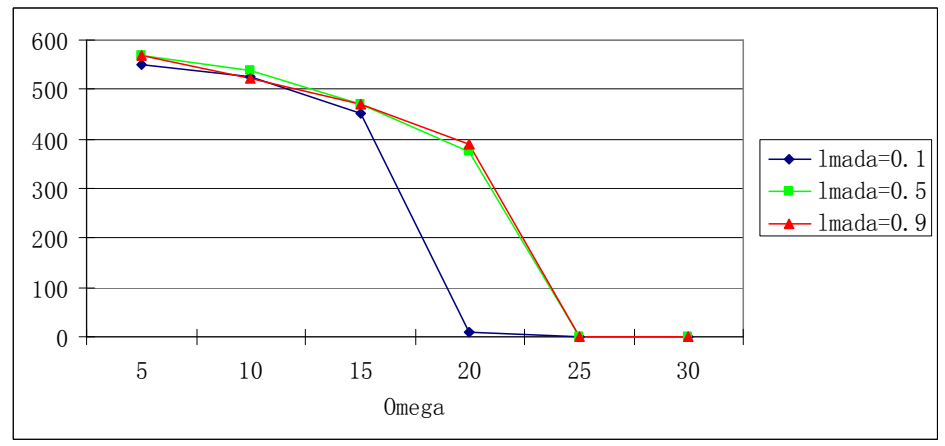

Figure 3 . Infeasibility when $\lambda$ keeps constant. 


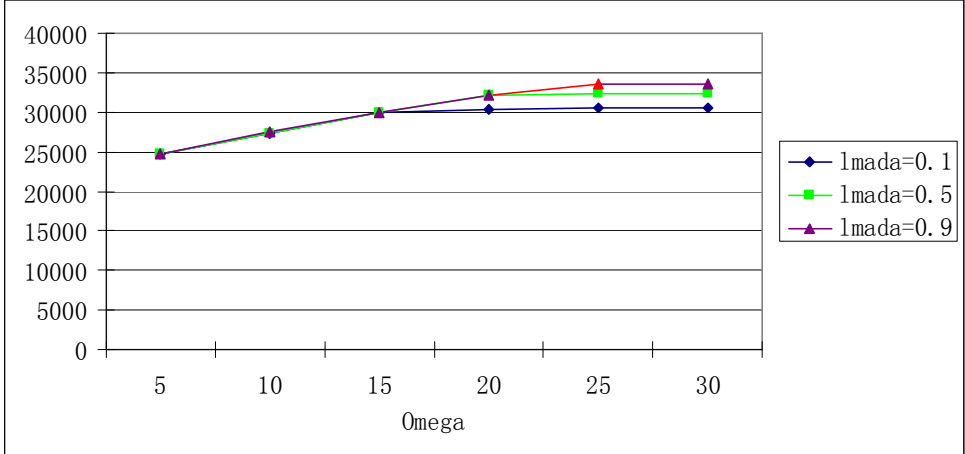

Figure 4. Total cost $\lambda$ keeps constant.

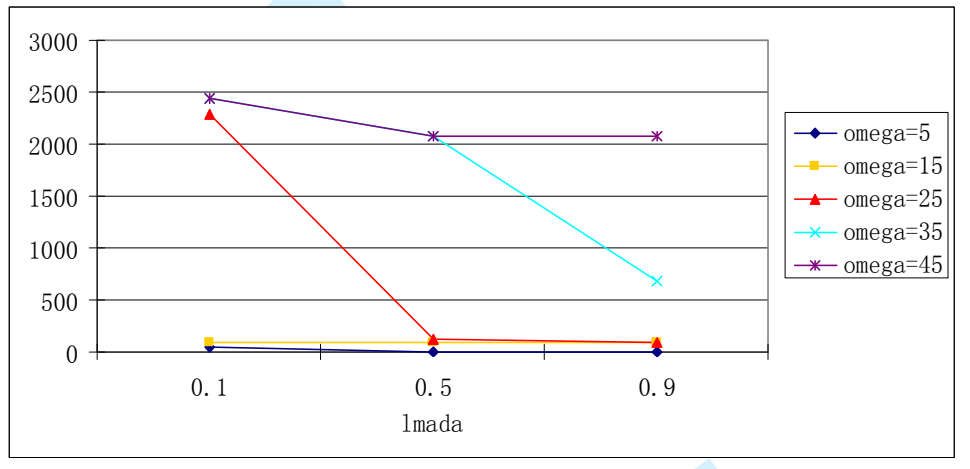

Figure 5. Variability when $\omega$ keeps constant.

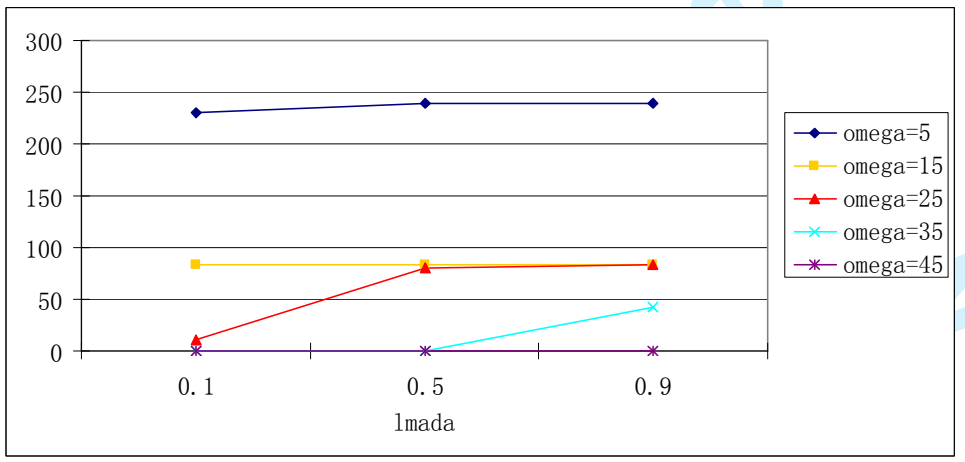

Figure 6. Infeasibility when $\omega$ keeps constant.

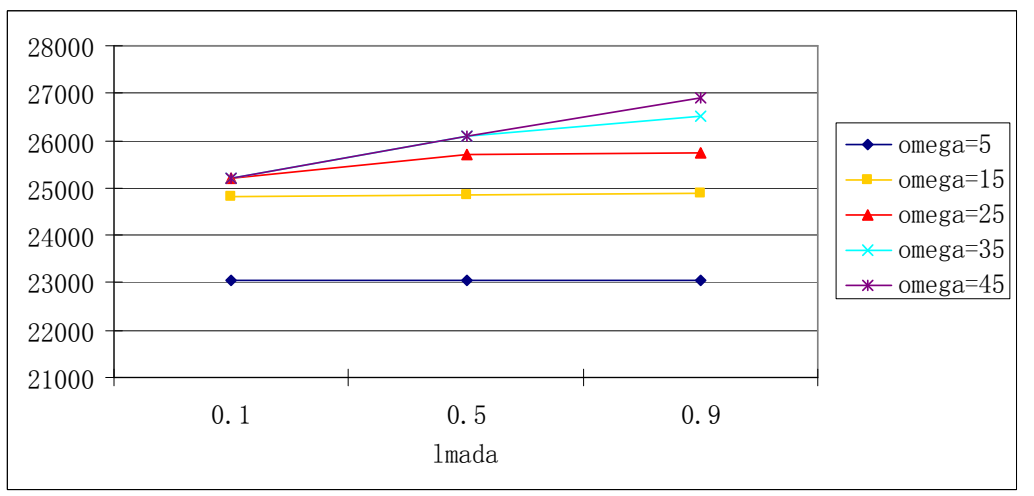

Figure 7. Total cost when $\omega$ keeps constant. 